\title{
El estado colombiano contra el reclutamiento ilegal 2005-2013*
}

\author{
Gloria Inés Romero Rodríguez** \\ Recibido: 20 de enero de 2014 • Revisado: 15 de febrero de 2014
}

Aprobado: 5 de marzo de 2014.

\section{Resumen}

El elevado número de menores de edad reclutados por los grupos armados ilegales en Colombia hace necesario que para la protección de los derechos humanos de los niños, niñas y adolescentes, se diseñen políticas públicas efectivas que los protejan de manera prevalente como lo ordena la Constitución Política, ya que lo que se puede concluir de la investigación documental realizada en esta investigación, en la que se tomó como periodo de estudio los años 2005 al 2013, por ser el periodo del actual Código de Procedimiento Penal del que existe información sobre la persecución al delito de reclutamiento ilícito; es que las acciones estatales referentes al tema no han sido lo suficientemente efectivas para separar a los menores de edad de los grupos armados ilegales que operan en Colombia. Así como tampoco se han reflejado en un trato adecuado al menor infractor, dando como resultado la creciente utilización de los menores en acciones criminales, tendencia que se ha visto disminuida en

\footnotetext{
"Este artículo presenta la investigación que desarrolló la autora sobre la eficacia de las políticas públicas emprendidas por el Estado colombiano para contrarrestar la vinculación de los menores de edad a los grupos organizados al margen de la ley que operan en el país. Lo anterior en el marco del proyecto de investigación: "Impunidad en el proceso Penal Colombiano", gestionado y patrocinado económicamente por la Corporación Universitaria Republicana.

"Magister en Intervención Social en las sociedades del conocimiento de la UNIR-España, licenciada en Ciencias Sociales de la Universidad Distrital Francisco José de Caldas, especialista en Informática Educativa de la Universidad Libre, especialista en Pedagogía para la Docencia Universitaria de la Fundación Universitaria del Área Andina y abogada de la Corporación Universitaria Republicana. Profesora en la Universidad Escuela Colombiana de Carreras Industriales y Coordinadora (e) del Grupo de Víctimas de la Defensoría del Pueblo en mayo de 2015. Correo electrónico: gloriainesromero@ yahoo.com.mx
} 
los últimos años debido a la iniciación del actual proceso de paz que se está dando entre el gobierno nacional y el principal grupo guerrillero que opera en el país.

Palabras clave: derechos humanos, menores de edad, reclutamiento ilícito, derechos de los niños, políticas públicas.

\title{
THE COLOMBIAN STATE AGAINST ILLEGAL RECRUITMENT FROM 2005 TO 2013
}

\begin{abstract}
The high number of children recruited by illegal armed groups in Colombia makes it necessary to devise effective public policies that protect prevalently for the protection of human rights of children and adolescents, as mandated by the Constitution because what can be concluded from the documentary research conducted in this investigation, which was taken as study period the years 2005 to 2013, being the period of the current Code of Criminal Procedure that exists about the persecution crime of illegal recruitment; It is that state actions concerning the issue have not been effective enough to separate minors from illegal armed groups operating in Colombia. Nor they have been reflected in a suitable treatment to juvenile offenders, resulting in the increasing use of children in criminal activities, a trend that has been diminished in recent years due to the initiation of the current peace process that is taking place between the national government and the main rebel group operating in the country.Keywords: human rights, minors, illegal recruitment, child rights, public policy.
\end{abstract}

Keywords: Human rights, minors, illegal recruitment, child rights, public policy.

\section{O ESTADO COLOMBIANO CONTRA O RECRUTAMENTO ILEGAL $2005-2013$}

\section{Resumo}

O elevado número de crianças recrutadas pelos grupos armados ilegais na Colômbia torna necessária a concepção de políticas públicas eficazes que protejam de forma predominante os direitos humanos de crianças e adolescentes, como manda a Constituição Política porque o que se pode concluir a partir da pesquisa documental 
realizada nesta investigação, que foi tomado como período de estudo os anos de 2005 a 2013, sendo o período de vigência do atual Código de Processo Penal que se tem informação sobre a perseguição a o crime de recrutamento ilegal; é que as ações estatais relativas à questão não foram suficientemente eficazes para que os menores sejam separados dos grupos armados ilegais que operam na Colômbia. Assim como também nem foram refletidas em um tratamento adequado para jovens delinquentes, dando como resultando no aumento da utilização de crianças em atividades criminosas, uma tendência que tem sido diminuído nos últimos anos devido ao início do atual processo de paz em curso que está ocorrendo entre o governo nacional e o maior grupo rebelde que operam no país.

Palavras-chave: direitos humanos, menores de idade, recrutamento ilegal, direitos das crianças, políticas públicas.

\section{Introducción}

Este artículo es el resultado de una investigación documental en la que a partir principalmente de los informes oficiales referentes al reclutamiento ilícito, se buscó medir la efectividad de las políticas públicas realizadas por el Estado colombiano durante el periodo de existencia del actual Código de Procedimiento Penal y que por razones de la información oficial existente, se restringió al periodo comprendido entre el año 2005 al 2013, intentando describir la eficacia de las acciones estatales para desvincular a los menores de los grupos armados ilegales que operan en $\mathrm{Co}^{-}$ lombia, así como para trazar programas y planes con los que se evitara la vinculación de ese grupo poblacional a las actividades criminales de las organizaciones armadas ilegales que operan en el país.

Es de señalar que la Constitución Colombiana de 1991 en el artículo 44 establece como derechos fundamentales para la infancia: el de la vida, la integridad física, la salud y la seguridad social, la alimentación equilibrada, el derecho a tener un nombre y nacionalidad, a tener una familia y a no ser separados de ella, al cuidado, a la educación, a la cultura, a la recreación y a la libre expresión. Estipulando que se protegerá a los menores contra toda forma de abandono, violencia física o moral, secuestro, venta, abuso sexual, explotación laboral o económica o trabajos riesgosos; y que los niños colombianos gozarán de los demás derechos consagrados en la Constitución, en las leyes y en los tratados internacionales ratificados por el país. Señalando que la familia, la sociedad y el Estado, tienen la obligación de 
asistir y proteger a los niños para garantizarles su desarrollo armónico e integral y el ejercicio pleno de sus derechos; por ello, cualquier persona puede exigir de la autoridad competente su cumplimiento y la sanción para los infractores. Por último, establece que por mandato constitucional los derechos de los niños prevalecen sobre los derechos de los demás.

El artículo 44 de la Constitucional Nacional es la base central para la protección de los menores en Colombia, de él se desprenden ciertas garantías que han sido utilizadas en acciones que protegen a la niñez. Pero al contrastar lo propuesto en la Carta Máxima respecto a los menores con lo que sucede en la realidad, se encuentra que el país presenta un escenario caracterizado por la violación de los derechos humanos -DH- de los menores y la ausencia de políticas públicas adecuadas para la protección y promoción de los niños y adolescentes. En Colombia todavía los menores de edad están vinculados a la vida laboral de forma legal o simulada, siguen realizando labores catalogadas entre las peores formas de trabajo infantil, se encuentran desamparados y son una porción importante de los cuerpos combatientes de los grupos armados ilegales que operan en el territorio nacional (Vicepresidencia de la República, 2011).

Según los informes oficiales, es alarmante el número de menores de edad vinculados penalmente por haber participado en acciones delictivas dentro de las que se destacan su participación en el tráfico de estupefacientes, homicidios, extorsiones, secuestro y terrorismo. La participación de los infantes y adolescentes en esta clase de ilícitos obedece a que son utilizados por los grupos delictivos, ya que el tratamiento jurídico que existe en el país para las personas menores de 18 años es poco organizado, generando impunidad para los que utilizan a los menores en acciones delictivas (Coalición contra la vinculación de niños, niñas y jóvenes al conflicto armado en Colombia 2009b).

Según el libro: El delito invisible, (Coalición contra la vinculación de niños, niñas y jóvenes al conflicto armado en Colombia 2009a), se estima que al menos uno de cada cuatro combatientes es menor de 18 años y que los menores pueden representar entre el 20 y 30 por ciento de los miembros de los grupos armados ilegales que operan en el territorio nacional, siendo los 12,8 años la edad promedio de ingreso. Esa situación existía antes de la Constitución del 91 y no ha cambiado mucho tras su expedición, principalmente por la continuidad del conflicto armado que genera condiciones de vulnerabilidad en la población infantil y la falta de políticas públicas eficaces que terminen con la vinculación de los menores de edad 
al conflicto armado (Springer, 2012). La vinculación de los menores a los grupos armados ilegales resulta de la combinación de varias circunstancias que hacen muy difícil probar quiénes son los responsables directos de ese delito. Los menores hacen parte de las fuerzas combatientes ilegales, producto de los escasos recursos de numerosas familias en las zonas rurales, especialmente en las zonas indígenas y de grupos afroamericanos, por la ausencia de programas públicos destinados a los menores de edad, faltan políticas públicas suficientes para atender integralmente a la infancia y la adolescencia; y son débiles los programas educativos para evitar la deserción escolar y la temprana vinculación de los menores a la vida laboral. Además, la inestabilidad familiar y la violencia intrafamiliar llevan a los menores de edad a salir tempranamente de sus hogares, y es ventajoso ocupar a los niños en el seguimiento de personas, mensajería, actividades riesgosas y para la explotación sexual, sobre todo de las niñas y las adolescentes (ICBF, 2012).

Sin embargo, es el desplazamiento forzado la principal causa del reclutamiento ilegal, porque genera condiciones de desarraigo e inestabilidad familiar, que aprovechan los grupos al margen de la ley para vincular a los menores a sus tropas. Según el Informe alterno al informe del Estado colombiano sobre el cumplimiento del Protocolo Facultativo Relativo a la Participación de Niños en los Conflictos Armados, la Corte Constitucional estima que el $50 \%$ de la población desplazada está constituida por personas menores de 18 años, dando como resultado que sean ellos el grupo de la población civil al que más se le vulneran sus derechos dentro de la confrontación armada que se vive desde hace décadas en Colombia. "Los niños y las niñas siguen siendo víctimas de reclutamiento, masacres, desplazamiento forzado, toma de rehenes, víctimas de minas antipersonal y violencia sexual con ocasión del conflicto armado" (Coalición contra la vinculación de niños, niñas y jóvenes al conflicto armado en Colombia 2009b, p. 17).

Al indicar que el conflicto armado es la principal razón para la vinculación de los menores a la guerra, se quiere resaltar que el reclutamiento ilícito no se puede desprender del conflicto armado y trabajarlo como una categoría independiente de él; lograr demostrar esta idea es uno de los propósitos de este artículo, debido a que con ocasión de los diálogos de paz de La Habana entre el gobierno colombiano y la guerrilla durante el segundo semestre de 2013, en Colombia viene exigiéndose que no sea tema de negociación la responsabilidad sobre el reclutamiento ilícito, se pide que la guerrillera responda por la vinculación de los menores al conflicto y que se hagan efectivos los compromisos asumidos por el Estado en el ámbito 
internacional al respecto. Pero lo que muestran los resultados oficiales ofrecidos por la Fiscalía General de la Nación-FGN-, sobre la persecución de este ilícito en el país, es que es muy baja la capacidad del Estado para perseguir a quienes lo cometen. En el periodo comprendido entre los años 2005 y 2013; solo hay un total de trece sentencias condenatorias ejecutoriadas, de las cuales 10 son por aceptación de cargos o como resultado de la negociación entre las partes. Resultados que permiten concluir que frente al alto número de menores vinculados al conflicto calculado en el año 2012 en unos 18.000, según el estudio Como corderos entre lobos de Natalia Springer, es mínima la acción de la Justicia para condenar a los culpables, pues el promedio es de dos sentencias por año en el periodo de vigencia del actual Código de Procedimiento Penal, 2005-2013 (Córdoba, 2013).

Los que reclaman en Colombia que el delito del reclutamiento ilícito no sea tema de la mesa de negociación de La Habana, por ser una acción criminal que exige ser penalizada; hacen una exigencia que genera más impunidad y no el fin de esa práctica. Las pocas condenas obtenidas, se deben a la complejidad probatoria de ese ilícito y a que la vinculación de los menores al conflicto armado resulta de la combinación de varios fenómenos sociales, como son las condiciones de pobreza y exclusión de numerosas familias y a la falta de un modelo educativo en el sector oficial que promueva el desarrollo armónico de los niños y los adolescentes. Factores que llevan a los menores a condiciones de vulnerabilidad social que son aprovechados por las organizaciones ilegales, que los ven como una fuente para aumentar el personal de sus organizaciones a bajo costo (ICBF, 2013b).

Una de las estrategias para evitar la incorporación de los menores a los grupos armados ilegales, es lograr que sea tema de negociación en La Habana, conviniendo acciones que permitan que una vez se llegue a un acuerdo de paz, los menores no serán vinculados a las organizaciones ilegales al trazarse mecanismos y acciones sociales que protejan a la infancia y la adolescencia de ser usados por la delincuencia organizada. Dentro de la justicia transicional es recomendable la creación dentro de la Comisión de la Verdad de un capítulo dedicado a la participación de los menores al conflicto; en el que los responsables describan los mecanismos soterrados con los que se realizaba la vinculación, los procedimientos a los que eran sometidos los menores dentro de las organizaciones armadas ilegales, las tareas que se les asignaban en la organización y los crímenes que se les destinaba a realizar. Proponiendo los integrantes de tales organizaciones desmovilizadas, recomendaciones que sirvan para trazar planes y programas que impidan la participación de los menores en los 
grupos ilícitos organizados. Y la información recopilada de la tarea propuesta debe ser tenida en cuenta en el diseño de políticas públicas que promuevan el respeto de los derechos humanos para la infancia y la adolescencia colombiana.

La actual Constitución de Colombia fue el resultado de un proceso de paz, a diferencia de lo ocurrido con las anteriores constituciones del país, por ello se esperaba que tras su expedición en 1991, se lograra consolidar un modelo político que condujera a la terminación del conflicto armado. Sin negar los avances en la protección de los $\mathrm{DH}$ en los últimos años y los mejores indicadores de violencia a nivel nacional, que se reflejan en la disminución de las cifras de la tasa de homicidios y del número de personas afectadas por el desplazamiento forzado, sigue presentándose una elevada violación de los $\mathrm{DH}$, siendo el grupo poblacional más vulnerable el de la Infancia, cuya situación "no ha mejorado, y al contrario las cifras referidas a los accidentes con minas y municiones sin explotar han aumentado entre 2011 y 2012" (Giraldo, 2013). Por ello, dedicar un artículo a describir cómo el Estado colombiano ha actuado contra el reclutamiento ilegal durante el periodo comprendido entre los años 2005 a 2013, implica realizar una evaluación sobre los alcances de las políticas públicas del Estado colombiano sobre el tema, que como se indica en Fundamentos de evaluación de políticas públicas del Ministerio de Política Territorial y Administración Pública. Agencia Estatal de Evaluación de Políticas Públicas y Calidad de los Servicios, exige entender que la evaluación es una valoración de lo público "con el fin de transformar lo que no funciona, pero no bajo premisas exclusivamente técnicas -aunque luego necesarias-, sino, también, de interlocución social que propicie una cultura de responsabilidad y mejora continua" (2010, p. 19).

\section{La protección de los derechos humanos en la Constitución de 1991}

La dignidad humana fue consagrada en el artículo primero de la Constitución de 1991, en el que se estableció que el Estado social de derecho colombiano, está fundado en el respeto de la dignidad humana; comprometiendo la Asamblea Nacional Constituyente a toda la sociedad en un proyecto político que haga posible el respeto de los DH y acabe con la violación de los mismos en el país. Esa tarea fue trazada como respuesta al momento histórico que se vivía en Colombia 
a principios de la década de los noventa, que se caracterizaba por un alarmante crecimiento de los grupos armados ilegales de la guerrilla y los paramilitares, los cuales violaban de manera sistemática y continua los DH y el Derecho Internacional Humanitario -DIH-, siendo la población civil la más afectada, problemática que todavía perdura en Colombia. Carlos Vidal menciona que el informe Basta Ya, del Grupo de Memoria Histórica creado por el Estado colombiano en el 2005, calcula en 220.000 las muertes causadas por el conflicto armado entre los años 1958 a 2012, "de los cuales el 80 \% fueron civiles inermes" (Amaya, 2013, p. 15) La Constitución de 1991, representa un importante avance en el constitucionalismo colombiano frente a la anterior Constitución de 1886. La nueva carta está en concordancia con los avances del constitucionalismo a nivel mundial, en ella los derechos no se entienden aisladamente, sino que en caso de conflicto entre ellos, se ponderan teniendo como guía el preámbulo que es vinculante y al Título I. De los principios fundamentales (Defensoría del Pueblo, 2003). En la Constitución del 91 se da primacía a la democracia participativa frente a la representativa, se incluye una amplia carta de derechos humanos, se busca el fortalecimiento institucional, se parte del principio de separación de poderes, se disminuye el poder presidencial y se conceden derechos a las regiones y a las localidades a partir de los principios de autonomía y la descentralización administrativa, se controlan los estados de excepción y las atribuciones especiales al ejecutivo, y se amplía la posibilidad de acceso al legislativo de nuevas fuerzas y grupos sociales, políticos y culturales, incluyendo las etnias indígenas y afrodescendientes (Olano, 2006). Además, la Constitución de 1991 contiene varias acciones, siendo la acción de tutela la más usada, por ser una acción judicial expedita para lograr la protección inmediata de los derechos fundamentales de los ciudadanos cuando son vulnerados o amenazados por la acción u omisión de la autoridad pública o de los particulares en algunos casos. Con la acción de tutela se busca garantizar la realización de los fines del Estado y con su adopción en el ordenamiento constitucional, se consagra una figura que protege de manera rápida los derechos fundamentales de los ciudadanos. "Antes de su implementación, el ciudadano común y corriente no tenía acceso a mecanismos coercitivos expeditos que permitieran brindarle resultados oportunos, en términos de protección" (Castillo, 2009, p. 37) a sus derechos fundamentales. La Corporación Excelencia en la Justicia a partir de la Encuesta Nacional de Necesidades Jurídicas Insatisfechas, realizada por la Cámara de Comercio de Bogotá, el Ministerio de Justicia y el Banco Mundial, comenta el reconocimiento que tiene entre los 
colombianos la acción de tutela, la cual presenta registros notoriamente mayores en comparación con otros mecanismos judiciales, como la acción de cumplimiento, la acción de grupo y la acción popular.

Se podría decir que este mecanismo, introducido en Colombia a partir de la Constitución de 1991, ha contado con una notable legitimidad y reconocimiento entre la ciudadanía. Y justamente los resultados de la encuesta dan soporte a esta apreciación. En efecto, los resultados de los sondeos aplicados a las 1.103 personas del grupo de "población en general", muestran que de este segmento poblacional un 83.7 \% manifestó tener conocimiento sobre la acción de tutela; a la vez que un 65 $\%$ afirmó tener una posición favorable acerca de dicho mecanismo (Corporación Excelencia en la Justicia, 2013)

El uso de la tutela obedece a los rápidos resultados en asuntos como la autorización de cirugías por parte de las entidades prestadoras de salud (EPS), la realización de tratamientos costosos para enfermos terminales o la entrega de medicamentos por fuera del plan obligatorio de salud (POS). "De las 3'321.457 acciones de tutela que los colombianos han interpuesto desde 1992 para invocar la protección de sus derechos fundamentales, 764.267, una cuarta parte del total, han estado relacionadas con la solicitud de servicios de salud" (eltiempo.com, 2012). También se utiliza para la obtención de respuestas en procesos judiciales, administrativos y en los que los particulares tienen el manejo de servicios públicos. Galo Blacio, señala que "la acción de tutela es informal en cuanto a su presentación, es decir que no se necesita de mayores tecnicismos en cuanto a su forma" (s.f.), lo que la convierte en un mecanismo de fácil acceso para cualquier persona. Su carácter sumario, permite la protección de los derechos fundamentales de quienes la invocan, especialmente por la población que no cuenta con los recursos necesarios para contratar una asesoría jurídica en la protección de sus derechos (Corporación Excelencia en la Justicia, 2013). La ausencia de orientación judicial entre la población pobre y de extrema pobreza, es un factor determinante para la falta de satisfacción de las necesidades jurídicas por estos grupos de personas, por lo que se reclama como un factor esencial para la promoción de los $\mathrm{DH}$ en el país, la formación cívica de la ciudadanía (Ibídem). Para educar a la ciudadanía en la búsqueda de una nueva cultura cívica, la Defensoría del Pueblo a través de la Dirección Nacional de Promoción y Divulgación de DH, en concordancia con una de las funciones asignadas en la 
Constitución de 1991 para el Defensor del Pueblo, de velar por la promoción, el ejercicio y la divulgación de los derechos humanos. Centra la acción educativa de la Defensoría del Pueblo de Colombia, en el Plan Nacional de Educación en DH -PLANEDH-, en cooperación con el Ministerio de Educación Nacional y la Vicepresidencia de la República, con el apoyo de la Oficina del Alto Comisionado de las Naciones Unidas para los DH y del Programa de DH de USAID. Adelanta también el Programa Nacional de Formación en DH de los Personeros Municipales, en cooperación con el Instituto de Estudios del Ministerio Público (Procuraduría General de la Nación) y con el apoyo de la Oficina del Alto Comisionado de las Naciones Unidas para los DH. Además, la Defensoría hace parte de la Red Nacional de Promotores de DH, en cooperación con la Escuela Superior de Administración Pública -ESAP- y varias Defensorías Regionales y Seccionales. Y cuenta con la cátedra «Ciro Angarita Barón», en cooperación con la Fundación Konrad Adenauer y la ESAP, el Programa Regionalizado de Gestión Defensorial, con el apoyo de la ASDI y el Plan Nacional de Formación para el Control Social en alianza con otras entidades del sector público. En cuanto a la divulgación de los DH, la Defensoría del Pueblo a través de la Defensoría Delegada de Seguimiento a las políticas públicas en $\mathrm{DH}$, realiza el seguimiento, evaluación y monitoreo a las políticas públicas que inciden en el logro y mejoramiento de las condiciones mínimas necesarias de vida digna, estableciendo el grado de realización de los derechos económicos, sociales y culturales en los grupos sociales más vulnerables. Le corresponde a la Defensoría Delegada de Seguimiento a las políticas públicas en DH cumplir las funciones de dirigir el Programa de Seguimiento y Evaluación de las Politicas Públicas en DH-ProSeDHer-, coordinar el macro proceso de investigación para la acción y coordinar el Observatorio de Justicia Constitucional. En la página web institucional, esta dependencia resalta que el mayor reto del Programa ProSeDHer es:

Lograr que las entidades a cargo del diseño, implementación y ejecución de las políticas públicas se apropien de la metodología no solo como procedimiento de evaluación y seguimiento permanente, sino como una guía para reformular las políticas públicas desde una perspectiva de derechos humanos, en el entendido de que el eje central de estas debe ser el sujeto y su relación con el entorno económico, social y cultural (Defensoría del Pueblo Colombia, 2013). 
En la Defensoría del Pueblo, existe la Defensoría Delegada de Prevención de Riesgos de Violaciones de DH y DIH, con la que se apoya la misión institucional de defensa de los DH y el DHI. Esta dependencia busca desarrollar y contribuir a una política defensorial preventiva sobre las posibles afectaciones a la población civil en el marco del conflicto armado interno, a través de instrumentos y metodologías institucionalizadas con las que se formulen recomendaciones a las autoridades del Estado para que brinden una atención integral. Entre las funciones de esta dependencia son de resaltar las siguientes: promover y apoyar la formulación e implementación de un Sistema Nacional de Prevención de Violaciones Masivas de los DH y el DIH en el contexto del conflicto armado interno; establecer mecanismos confiables y eficaces de información que busquen el mejoramiento de las respuestas estatales y sociales a las amenazas que sufren las comunidades expuestas a las consecuencias del conflicto armado interno; dirigir el proceso de recepción, registro, clasificación evaluación e interpretación de la información pertinente para diagnosticar situaciones de riesgo de la población civil en conflicto armado; identificar el mapa de riesgo nacional en el marco del conflicto armado interno; dar a conocer el Sistema de Alertas Tempranas como instrumento para la Prevención de Violaciones Masivas de DH; y emitir informes ante situaciones de inminencia, para advertir a las autoridades competentes sobre el riesgo a que se ven sometidas las comunidades en el contexto del conflicto armado interno y realizar el seguimiento a las respuestas de las entidades concernidas monitoreando la evolución del riesgo advertido. Esta dependencia presta el servicio del Sistema de Alertas Tempranas (SAT), con el que la Defensoría del Pueblo acopia, verifica y analiza de manera técnica información relacionada con situaciones de vulnerabilidad y riesgo de la población civil, como consecuencia del conflicto armado y advierte a las autoridades concernidas con deber de protección, para que coordinen y brinden atención oportuna e integral a las comunidades afectadas (Ibídem). Respecto a los menores de edad, existe la Defensoría delegada para los derechos de la niñez, juventud y las mujeres, que es una unidad asesora del Despacho del Defensor del Pueblo y lo aconseja en todo lo relacionado con la divulgación, protección y promoción de los DH de los grupos a su cargo, así como con el seguimiento de las políticas públicas que propenden por su realización efectiva. Entre sus funciones está: evaluar la situación de los DH en Colombia en relación con la materia de su especialidad y sugerir al Defensor del Pueblo la formulación de observaciones o denuncias de carácter general, establecer comunicación permanente y compartir información 
con las organizaciones gubernamentales y no gubernamentales de protección y defensa de derechos humanos en su área respectiva, y la de apoyar y asesorar a las demás dependencias de la institución en las materias propias de su especialidad. Esta dependencia ha venido trabajando en el tema relacionado con la reforma de la legislación de Infancia y Adolescencia en Colombia (Ibídem). En un comunicado de prensa de la Oficina del Alto Comisionado de las Naciones Unidas para los DH OACNUDH-UNHCHR, se resalta la importancia del Defensor del Pueblo, a quien se le califica como el ombudsman o servidor público encargado de velar por la promoción, el ejercicio y la divulgación de los derechos humanos, resaltando que la independencia del Defensor del Pueblo es un requisito indispensable para que "pueda desempeñar eficazmente su magistratura de influencia constructiva y de mediación. Esa magistratura constituye un valioso elemento para la defensa y el desarrollo de la democracia colombiana" (OACNUDH-UNHCHR, 2003).

Por último cabe mencionar, en lo que se refiere a la protección de los $\mathrm{DH}$ en la Constitución de 1991, el artículo 93 el cual contempla que los tratados y convenios internacionales ratificados por el Congreso, que reconocen los $\mathrm{DH}$ y que prohíben su limitación en los estados de excepción, prevalecen en el orden interno. Y además establece que los derechos y deberes consagrados en la Constitución se interpretarán de conformidad con los tratados internacionales sobre $\mathrm{DH}$ ratificados por Colombia. Rodrigo Uprimny, profesor de la facultad de Derecho de la Universidad Nacional y magistrado auxiliar de la Corte Constitucional, comenta que "todavía no es claro cuáles son las normas y principios que integran el bloque en sentido estricto o en sentido lato" (Uprimny, 2006, p. 27). Por otra parte, Álvaro Amaya al comparar la diferencia entre el concepto de núcleo duro y núcleo esencial propuesto por la jurisprudencia de la Corte Constitucional colombiana, para verificar si lo que la Corte entiende como núcleo esencial de los derechos fundamentales coincide con el propuesto por la doctrina internacional como núcleo duro de los $\mathrm{DH}$, destaca que los pronunciamientos de la Corte son ambiguos al tratar el término núcleo esencial de los derechos. "Decimos esto, porque a pesar de que en ocasiones pareciera asimilar este concepto con el de 'núcleo duro de los derechos humanos', sus conclusiones apuntan a un concepto diferente" (Amaya, 2013, p. 56). La ausencia de un ejercicio propio de conceptualización respecto del artículo 93 de la Constitución, por el que se incorpora el Bloque de Constitucionalidad al país, genera una confusión en cuanto al sentido de los términos que afecta la aplicación de los tratados y convenios internacionales sobre los $\mathrm{DH}$, haciendo urgente corregir esa situación, con 
el fin de armonizar los términos del derecho interno con los del contexto mundial. Ejemplo de los equívocos en la aplicación de los tratados ratificados por Colombia, es lo que sucede con lo que se entiende por suspensión de derechos. Amaya describe así el problema:

Las normas deberían dar el mismo sentido a los términos, sin embargo la legislación nacional utiliza el verbo 'suspender' en el sentido de no afectar los elementos esenciales del derecho, mientras que la internacional, según interpretación autorizada ya referida en este texto, 'suspender' es sinónimo de imposibilidad de limitación alguna (esto incluye los elementos esenciales como los no esenciales del derecho humano correspondiente) (2013, p. 74).

La ambigüedad conceptual de la jurisprudencia constitucional, obliga a los encargados de su aplicación a reforzar la rigurosidad en el tratamiento terminológico para que las interpretaciones legales que ofrezcan sean sólidas y "permitan garantizar jurídicamente los derechos humanos, tanto en su plano constitucional, como internacional" (Amaya, 2006, p. 92). Por ahora la jurisprudencia de la Corte con respecto al bloque de constitucionalidad favorece, como indica Uprimny (2006), la adaptación histórica de la Constitución a las nuevas realidades sociales y políticas, dando el carácter de documento viviente a la Carta Máxima. En el momento de actuar, el marco jurídico de la Constitución del 91 enfrenta el reto de proponer soluciones jurídicas que respondan a los compromisos pactados por el Estado y al mismo tiempo, llenar los vacíos terminológicos con propuestas que hagan viable el proceso de paz en Colombia, asegurando el respeto a los DH y el DIH. Quizás el clásico fallo de la Corte Suprema de los Estados Unidos en el caso Marbury v. Madison de 1803, cuando señala:

La terminología especial de la Constitución de los EE. UU. confirma y enfatiza el principio, que se supone esencial para toda Constitución escrita, de que la ley repugnante a la Constitución es nula, y que los tribunales, así como los demás poderes, están obligados por ese instrumento (Barrero 2013, p. 67).

Lo anterior puede servir de luz a la jurisprudencia nacional para contribuir al fin del conflicto armado. Partiendo, como también lo indica el fallo Marbury v. 
Madison que "el pueblo tiene el derecho preexistente de establecer para su gobierno futuro los principios que juzgue más adecuados a su propia felicidad” (Barrero, 2013, p. 67). La Corte Constitucional ha enfatizado que los tratados de DH internacionales que protegen los derechos fundamentales de los menores hacen parte del bloque de constitucionalidad. En este sentido, los DH de los menores en el país se han ido desarrollando no solo con base en el marco constitucional que les otorga una protección especial, sino también alrededor de los tratados internacionales de DH que los protegen, "la gran mayoría de los derechos sociales como lo son la educación y la salud son derechos que sin necesidad de establecer conexidad alguna se tornan para éstos derechos fundamentales del mismo estatus que el derecho a la vida” (Arango, 2006, p. 94).

\section{El delito del reclutamiento ilícito en Colombia}

En el Código Penal Colombiano, Ley 599 de 2000, en la parte especial, en el título II: delitos contra personas y bienes protegidos por el Derecho Internacional Humanitario, capítulo único, se estipula en el artículo 162, el delito de Reclutamiento Ilícito, con el que se establece que quien con ocasión y desarrollo del conflicto armado reclute menores de dieciocho años o los obligue a participar directa o indirectamente en las hostilidades o acciones armadas; será castigado con una pena entre 8 a 15 años y deberá pagar una multa de ochocientos a mil quinientos salarios mínimos legales mensuales vigentes ${ }^{1}$. El título II del Código Penal, resulta de los compromisos internacionales del Estado colombiano en la protección de los DH y el DIH, en concordancia con la Constitución Nacional que adscribe al orden interno en forma prevalente los Tratados Internacionales ratificados por el país relacionados con la protección de los $\mathrm{DH}$. El capítulo único del título II, comprende los delitos de homicidio, lesiones personales, tortura, acceso carnal violento, actos sexuales cuando se cometan en persona protegida. Además incluye la prostitución forzada o esclavitud sexual, utilización de medios y métodos de guerra ilícitos, perfidia, actos de terrorismo, tratos inhumanos y degradantes y experimentos biológicos en persona protegida, actos de discriminación racial, toma de rehenes, detención ilegal y privación del debido proceso con ocasión del conflicto armado, constreñimiento o apoyo bélico, despojo en el campo de batalla,

\footnotetext{
${ }^{1}$ La Ley 890 de 2004 en el artículo 14 aumentó las penas establecidas en la Ley 599 de 2000.
} 
omisión de medidas de socorro y asistencia humanitaria, obstaculización de tareas sanitarias y humanitarias, destrucción y apropiación de bienes protegidos, destrucción de bienes e instalaciones de carácter sanitario, destrucción o utilización ilícita de bienes culturales y de lugares de culto, ataque contra obras e instalaciones que contienen fuerzas peligrosas, represalias, atentados a la subsistencia y devastación, omisión de medidas de protección a la población civil, reclutamiento ilícito, exacción o contribuciones arbitrarias y destrucción del medio ambiente, "los mencionados delitos tienen unos antecedentes en la legislación internacional y se estructuran en el ámbito de un conflicto armado nacional, es decir diferente a cualquier otro de carácter internacional" (Arboleda y Ruiz, 2008, p. 1.399). Esos delitos ocurren en el conflicto armado colombiano, constituyéndose en acciones con las que se violan los DH y el DIH no solo de los combatientes, sino principalmente de la población civil (Coalición contra la vinculación de niños, niñas y jóvenes al conflicto armado en Colombia 2009a). El delito de reclutamiento ilícito está en concordancia con los artículos 2, 12, 13, 44 y 93 de la Constitución Nacional y a nivel internacional con la Convención sobre los Derechos del Niño; el artículo 4, numeral 3 del Protocolo II adicional a los Convenios de Ginebra del 12 de agosto de 1949 y; el artículo 77 del Protocolo I adicional a los Convenios de Ginebra del 12 de agosto de 1949. (Pabón, 2012, p. 150). La intención de apartar a los menores del conflicto interno es clara por parte del legislador colombiano al contemplar el delito de reclutamiento ilícito dentro del capítulo destinado a la protección de personas y bienes protegidos por el DIH. Este capítulo promueve "la defensa del ser humano y de los bienes necesarios para su mínimo bienestar y supervivencia, así como de aquellos que se erigen como indispensables para la preservación cultural" (Pabón, 2012, p. 99); intentando a través de estas normas humanizar la guerra al establecer unas reglas mínimas a los bandos armados enfrentados. La prohibición del código penal del reclutamiento de menores de edad, deja clara la violación al DIH por cualquier grupo armado que los recluta en sus filas. Prohibición concordante con los intereses de la comunidad internacional que una vez terminada la Segunda Guerra Mundial, buscó a través de la Declaración Universal de los DH de 1948 y los demás tratados referentes al tema, humanizar los conflictos bélicos, resguardar la dignidad humana y proteger a los menores.

La humanización de la guerra por parte del derecho internacional de los derechos humanos busca erigir como principios y postulados de carácter absoluto el respeto 
por la vida de las personas, su integridad y libertad fundamentado en la razón onto-

lógica del hombre: la dignidad humana (Arboleda y Ruiz, 2008, p. 1.408).

Hace parte de la dignidad humana el permitírseles a las personas disfrutar cada ciclo de su vida, entendiendo que la niñez es un estadio central para cada persona, por lo que se le debe asegurar a los menores desarrollarse armónicamente. Bajo este entendido, la Constitución Nacional aplica el principio de corresponsabilidad entre el Estado, la familia y la sociedad para la protección de la niñez, comprometiendo así a toda la sociedad en la protección de los menores de edad. La evaluación del compromiso del Estado colombiano en la protección de los $\mathrm{DH}$ y fundamentales de los menores a partir de la Constitución de 1991, muestra un resultado poco alentador después de dos décadas de expedición de la carta constitucional. Siendo el problema de los menores vinculados a los grupos armados ilegales, el que genera un mayor reto para las políticas públicas relacionadas con la defensa de los $\mathrm{DH}$, dado que en el reclutamiento de niños para la guerra, confluyen tres de los mayores problemas de la sociedad colombiana, como son: el desplazamiento forzoso, el recrudecimiento del conflicto armado y el aumento de injerencia de la delincuencia organizada dentro de la sociedad. El Nuevo Herald indica que Colombia es el cuarto país del mundo con más niños vinculados al conflicto armado en el año 2004, estando el número de menores combatientes por debajo solamente de los existentes en la República Democrática del Congo, Liberia y Birmania. Además, el Nuevo Herald resalta que el delegado del Fondo de Naciones Unidas para la Infancia, Jorge Balles, señaló que la UNICEF considera que los menores son sujetos pasivos del delito, obligados por los adultos a participar en la guerra, y que el reclutamiento de los menores, afecta de manera negativa a toda la sociedad colombiana presente y futura, porque hace que los niños crezcan en un ambiente bélico y se acostumbren a él.

Es grave para cualquier país el que haya un número tan elevado de niños en la guerra. Los niños son los adultos del mañana y evidentemente nunca es positivo que una sociedad herede personas que han crecido en entornos violentos (Nuevo Herald, 2004).

Por otra parte, la revista Semana informó en el 2012, que el secretario general de Naciones Unidas, Ban Ki-moon, manifestó su preocupación sobre las graves violaciones de las que son objeto los niños colombianos, entre las que se encuentran 
el reclutamiento y la utilización por grupos armados, las muertes y las mutilaciones, los actos de violencia sexual, los secuestros, los ataques contra escuelas y hospitales y la denegación del acceso humanitario. El alto funcionario recomendó al Estado colombiano reforzar las medidas de protección de los niños afectados por el conflicto armado; exigiendo a la menor brevedad la desvinculación de los menores de los grupos armados ilegales y resaltando la tarea de dar prioridad a ese punto en un posible diálogo de paz. "Con respecto a la impunidad, el organismo pide un avance más rápido al comparecer ante la justicia a los responsables de cometer graves violaciones de los derechos de los niños” (Semana, 2012). En el informe del secretario general de Naciones Unidas sobre el reclutamiento y utilización de niños en el conflicto armado se advierte un aumento de casos, indicando que el reclutamiento en Colombia comienza a los 9 o los 10 años de edad, y que "Las FARC utilizan a los niños para fabricar y colocar minas terrestres, comprar medicinas y realizar tareas de inteligencia" (Ibídem), dando a conocer el caso de un menor que fue utilizado como terrorista suicida en marzo de 2010, cuando usaron "a un niño de 12 años para portar explosivos" (Ibídem). Según la Comisión de Seguimiento a la Política Pública sobre Desplazamiento Forzado en el 2008, "unas 2.600 familias desplazadas denunciaron el reclutamiento como causa de su desplazamiento" (Ibídem). Todo ello lleva a que el informe recomiende un trato de víctima al menor infractor vinculado a los grupos armados ilegales.

'Los niños que han sido separados de grupos que el gobierno considera criminales no deben ser remitidos al sistema de justicia penal y, por el contrario, deben ser tratados como víctimas y gozar de la misma protección de los niños que hayan sido separados de grupos guerrilleros', indica el informe, que pide a los grupos armados darle fin al uso de las minas antipersonal y facilitar su remoción (Ibídem).

El Código de la Infancia y de la Adolescencia, Ley 1098 de 2006, realiza importantes reformas respecto de la responsabilidad penal de los menores de edad en Colombia, y dicta nuevas normas procedimentales para los mismos. En el artículo 139 , establece que el sistema de responsabilidad penal para adolescentes comprende los principios, normas, procedimientos, autoridades judiciales especializadas y entes administrativos que rigen o intervienen en la investigación y juzgamiento de delitos cometidos por los menores de dieciocho años y mayores de catorce. En el artículo 140, estipula que en materia de responsabilidad penal para adolescentes, 
dentro del proceso, las medidas que se adopten deben ser de carácter pedagógico, específico y diferenciado respecto del sistema de adultos, conforme a la protección integral. Resaltando que las autoridades judiciales deben siempre privilegiar el interés superior del niño y orientarse por los principios de protección integral, pedagógicos, específicos y diferenciados que rigen el sistema de responsabilidad penal del menor, sin permitir en ningún caso, que la protección integral del adolescente sirva de excusa para violarle sus derechos y garantías constitucionales. El artículo 143 del mismo código, contempla que al menor de catorce años que incurra en la comisión de un delito, solo se le aplicarán medidas de verificación de la garantía de sus derechos, su restablecimiento y que será vinculado a procesos de educación y de protección dentro del Sistema Nacional de Bienestar Familiar, en los cuales se observarán todas las garantías propias del debido proceso y el derecho de defensa. Además, que el Instituto Colombiano de Bienestar Familiar-ICBF-, establecerá los lineamientos técnicos para los programas especiales de protección y restablecimiento de derechos de los menores de catorce años que hayan cometido delitos. Entendiendo que la protección integral de los menores en la Ley 1098 de 2006, "se refiere a su reconocimiento como sujetos de derechos, la garantía y cumplimiento de los mismos, la prevención de su amenaza o vulneración y la seguridad de su restablecimiento inmediato en desarrollo del principio del interés superior" (Giraldo, 2013, p. 68). La Ley 1098 de 2006, reemplazó al Decreto 2737 de 1989 "Código del Menor", actualizando la normatividad colombiana respecto a la responsabilidad penal de los adolescentes, incorporando dentro de la jurisdicción nacional aportes de la Convención sobre los Derechos de los Niños de la ONU de 1989; de las Reglas minimas de las Naciones Unidas para la administración de la justicia de menores de 1984, (Reglas de Beijin); y de las Directrices de las Naciones Unidas para la prevención de la delincuencia juvenil, Resolución 45/112 de 1990, (Directrices de $R L A D)$. Respondiendo el legislador colombiano a la necesidad de modernizar el proceso penal para los menores de edad y protegerlos de las arbitrariedades que eran posibles con el anterior Código del Menor. Lamentablemente, la protección al menor por el Nuevo Código de la Infancia y la Adolescencia, ha dado como resultado que los grupos al margen de la ley utilicen a los niños, niñas y adolescentes para cometer delitos, por no ser tan duras las penas para ellos. Según Europa Press, más del sesenta por ciento de los delitos cometidos en Colombia son realizados por menores de edad, "de cada 100 delitos, 65 son cometidos por niños y jóvenes con edades entre los 13 y 18 años (Europa Press, 2013). 
La utilización de los menores por la delincuencia organizada y el reclutamiento ilícito por partes de los grupos armados irregulares que operan en el país, ha sido enfrenta por parte del ICBF (entidad estatal colombiana, encargada de la protección integral de la primera infancia, la niñez, la adolescencia y el bienestar de las familias en Colombia); con la creación y puesta en marcha de varios planes y programas, siendo de resaltar el Programa de atención especializada a niños, niñas y adolescentes desvinculados de los grupos armados organizados al margen de la ley, puesto en marcha, desde 1999. Programa que tiene como objetivo restablecer los derechos de las víctimas del delito de reclutamiento ilícito apoyando sus procesos de integración familiar, social y comunitaria. Hasta el 2012 el ICBF había recibido a 5.156 niños, niñas y adolescentes que huyeron o fueron recuperados de los grupos armados al margen de la ley (ICBF, 2012, p. 1). El ICBF en el 2013, informó que los grupos armados ilegales tienen menores de edad desde la primera infancia (entre los $0 \mathrm{y}$ 5 años). "Sin embargo, se sabe que es desde los seis que empiezan a someterlos a las actividades de sus cuadrillas y a utilizarlos en las tareas del combate" (ICBF, 2013b, p. 1). Sin negar la función desarrollada por el ICBF desde su creación en 1970, el Instituto ha sido permeado por la corrupción administrativa, fenómeno recurrente en la administración pública colombiana ${ }^{2}$. El problema de la corrupción es tema central del debate público en el país a finales del 2013 por la destitución del alcalde de Bogotá Gustavo Petro, quien dentro de su administración denunció importantes casos de corrupción en el Distrito Capital y cuando era congresista, atacó la corrupción a nivel nacional ${ }^{3}$. Un ejemplo de la corrupción dentro del ICBF, se registró en el Departamento de Chocó, zona del país con 81,94 \% de personas con Necesidades Básicas Insatisfechas -NBI-, según el Censo General 2005 de Colombia actualizado en junio de 2011 por el Departamento Administrativo Nacional Estadísticas -DANE-. En el Chocó, en agosto de 2011, la policía decomisó

\footnotetext{
${ }^{2}$ Colombia en el escalafón de Transparencia Internacional, el Índice de Percepción de Corrupción (IPC) del 2011 fue 3,4 sobre 10, pasando de la posición 78 en el año 2010 a la 80 en el 2011. En el 2011, 134 de 183 países recibieron una calificación por debajo de 5,0, en una escala de 0 (altos niveles de percepción de corrupción) en medio de un contexto de protestas ciudadanas contra la corrupción y la inestabilidad económica. "Este año hemos visto la corrupción en las pancartas de los manifestantes, en países ricos y pobres" (Portafolio, 2011).

${ }^{3}$ Gustavo Petro, exguerrillero del M-19 que se desmovilizó en 1990, fue electo por votación popular el 30 de octubre de 2011. Desde octubre de 2013 el alcalde Petro demandó al Estado colombiano ante la Comisión Interamericana de Derechos Humanos (CIDH) por la persecución y violación de sus derechos políticos como alcalde de Bogotá. E1 9 de diciembre de 2013 fue destituido de su cargo como alcalde de Bogotá por el Procurador General de la Nación.
} 
tres toneladas de bienestarina en un camión que tenía como destino a un criadero de cerdos. "El producto de alto valor nutricional para los niños más pobres y en riesgo de desnutrición, era transportado en 146 bultos" (Territorio Chocoano, 2011). La bienestarina "es entregada a los beneficiarios de los programas de Bienestar Familiar y a la población más vulnerable del país”, (ICBF, 2013a) pero por la corrupción existente no llega siempre a la población para la que está destinada. En el Chocó, en el año 2007, ocurrió otro caso similar, se incautó en una finca bienestarina que era usada en un criadero de cerdos, por ese caso la Fiscalía anunció que las personas involucradas "podrían ser procesadas por el delito de 'homicidio doloso"” (Territorio Chocoano, 2011), pues en el 2007 varios niños chocoanos murieron por desnutrición.

En Colombia, se puede decir que tanto la atención al menor vinculado a los grupos armados como al que se encuentra en estado de vulnerabilidad, es débil debido a la corrupción administrativa, la falta de conciencia social sobre el valor de la infancia y por la ausencia de mecanismos judiciales que eviten la impunidad sobre el tema. Las estadísticas sobre la efectividad del Estado en la persecución del delito de reclutamiento ilegal son muy bajas, en la respuesta de la Dirección Nacional de Fiscalías, al derecho de petición interpuesto por la autora de este artículo para conocer los datos oficiales, la fiscal seccional María Córdoba informó que el número de sentencias por el delito de reclutamiento de niños, niñas y adolescentes en Colombia es de 13 personas condenadas, según el sistema de información SPOA a partir del año 2005 hasta el 2013; es decir por año se condena en promedio a 1,625 personas (Córdoba, 2013), resultado muy bajo en comparación con el número de menores vinculados a los grupos armados ilegales. A la FGN por mandato constitucional, le corresponde adelantar investigaciones por el delito de reclutamiento ilícito y generar acciones efectivas a la salvaguarda de los derechos fundamentales de las víctimas en el contexto del conflicto armado, teniendo en consideración el carácter de sujetos de protección especial por mandato constitucional de los menores de edad. Por ello la Dirección Nacional de Fiscalías implementó el Plan Integral de Acción para su Defensa que comprende la construcción de una base diferencial y exclusiva para los casos de reclutamiento ilícito, gracias a la cual ha identificado en los distintos despachos fiscales y direcciones seccionales 2.641 investigaciones, de las cuales se encuentran activas $1.849,1.366$ referentes a niños y 592 a niñas. También gracias a la información recopilada ha identificado que los grupos poblacionales más afectados son los indígenas y afrodescendientes según los reportes de las Direcciones Seccionales de 
Fiscalías. "Adicionalmente se encontró de manera preliminar, que el principal actor armado perpetrador de estos hechos son las guerrillas colombianas" (Ibídem, p. 2).

La FGN, en las investigaciones sobre reclutamiento ilícito adelanta una investigación diferencial a partir de las directrices de: asociación de casos de acuerdo a la zona y fecha de ocurrencia de los hechos victimizantes; abordaje y tratamiento diferencial de protección y rehabilitación en favor de las víctimas; articulación interna e interlocución interinstitucional con el ICBF y la Alta Consejería para la Reintegración; definición de la geo referenciación con base en la incidencia de los delitos; investigaciones debidamente contextualizadas frente a patrones de comportamiento y calidad de los perpetradores; canalización oportuna de situaciones que ameritan riesgo para las víctimas, testigos y funcionarios encargados de las investigaciones. Con base en las investigaciones, la FGN realiza comités técnicos jurídicos de casos, con los cuales se busca promover el trámite eficiente en la persecución de ese delito. En la directriz de articulación intra institucional, la FGN participa en actividades de prevención con voz pero sin voto, en la Comisión Intersectorial para la prevención del reclutamiento, la utilización y la violencia sexual contra niños, niñas $y$ adolescentes por grupos armados al margen de la ley y grupos delictivos organizados. Además, la FGN contribuye en la búsqueda del Estado de mecanismos que permitan la implementación de las observaciones hechas por el Secretario General de las Naciones Unidas y los demás organismos internacionales en sus informes, sobre la prevención de los menores vinculados al conflicto armado en Colombia. Conflicto que "es monitoreado por el Mecanismo de Supervisión y Presentación de informes sobre niños y conflictos armados establecido por la resolución 1612 del Consejo de Seguridad (conocido como Task Force)" (Ibídem, p. 4).

\section{Comisión Intersectorial para la prevención del reclutamiento, la utilización y la violencia sexual contra niños, niñas y adolescentes por grupos armados al margen de la ley y grupos delictivos organizados}

La Comisión Intersectorial es presidida por el vicepresidente de la República, en el Decreto 552 de 2012 en el artículo 3, establece en los numerales del 2 al 23 los funcionarios que actúan con voz y voto. $Y$ en el parágrafo 1 , indica que el procurador general de la nación, el fiscal general de la nación y el defensor del pueblo 
podrán ser invitados permanentes con voz pero sin voto. La Comisión surgió por iniciativa del Ministerio de Relaciones Exteriores, una vez el Estado colombiano se sometió de manera voluntaria al monitoreo y presentación de informes de la Resolución 1612 de 2005 del Consejo de Seguridad de Naciones Unidas. Básicamente la Comisión Intersectorial, es un grupo de trabajo creado por el propio Estado para prevenir el reclutamiento y utilización de los menores por los grupos al margen de la ley, que tiene como tarea principal adelantar acciones que contribuyan en la prevención del reclutamiento, utilización y violencia sexual de los menores de 18 años, por los grupos armados organizados al margen de la ley. Dentro de su gestión es de resaltar el desarrollo de la política intersectorial en más de 110 municipios de 30 departamentos y 6 localidades de Bogotá; la construcción de las Rutas de Prevención de Reclutamiento con las entidades de la Comisión Intersectorial; el acompañamiento y asesoría en el Task Force; la asesoría Técnica y acompañamiento con el fin de fortalecer las mesas de prevención de reclutamiento en los departamentos de Antioquia, Tolima, Meta, Cesar y Chocó; la cartilla Prevenir el reclutamiento y la utilización: una tarea de todos; y el Proceso de regionalización, por el cual desde el año 2011 la Secretaría Técnica fortalece su presencia regional con asesores ubicados en los departamentos de Bolívar, Boyacá, Cauca, Meta, Nariño, Tolima, Chocó y Valle del Cauca, aunque espera tener presencia gradualmente en los 32 departamentos (Vicepresidencia, 2011).

La Secretaría Técnica de la Comisión Intersectorial desde el año 2013 adelanta un trabajo tendiente a impulsar y visibilizar las investigaciones y procesos adelantados en relación con el reclutamiento ilícito, uso de menores en actividades delictivas y violencia sexual en el marco del conflicto armado en contra de niños, niñas y adolescentes. En respuesta al derecho de petición interpuesto por la autora de este artículo, la directora encargada del Programa Presidencial de DDHH y DIH, señaló que los datos recolectados por la Secretaría hasta el momento, arrojan el siguiente resultado: " 22 sentencias de jurisdicción ordinaria y 4 de Justicia y Paz, para un total de 26 fallos en materia de reclutamiento ilícito" (Herrera, 2013, p. 2), en el periodo comprendido entre los años de 2009 a 2013; de las cuales 20 de las 22 sentencias de la jurisdicción ordinaria son de primera instancia, al igual que las 4 de Justicia y Paz. Dando como resultado, que en primera instancia en el periodo comprendido entre el año 2009 al 2013, en Colombia en promedio se han dado 5,5 condenas por año en la jurisdicción ordinaria y 1 en Justicia y Paz. 


\section{Conclusiones}

En Colombia cuando lo que se dice es muy diferente con lo que se hizo, se usa la frase: "Una cosa es lo que dice el dicho y otra es la que dice el cuento". Nada mejor que este refrán popular para resumir lo expuesto en este artículo con respecto a la protección de los derechos humanos de los menores de edad, pues aunque existe un marco jurídico suficientemente amplio para su protección, empezando por la Constitución que estipula que todos los derechos de los niños son fundamentales y por el Código penal que prohíbe el reclutamiento de los menores para la guerra, a que existen planes y programas estatales para la atención de los menores vinculados al conflicto armado y para prevenir esa clase de reclutamiento ilegal, por problemas de corrupción administrativa, de falta de mecanismos eficaces para hacer cumplir las normas y la ausencia de políticas públicas comprometidas con la erradicación de ese delito, han dado como resultado que cada día sea mayor el número de menores vinculados al conflicto armado. Es decir, la protección al menor es más formal que real, dada la falta de estrategias que aseguren el cumplimiento normativo y de planeación existente. Siendo conveniente resaltar que no solamente se violan los derechos de los menores, sino que es constante el desconocimiento de los derechos fundamentales en Colombia, muestra de ello es el elevado número de acciones de tutela invocadas a diario en el país.

Frente a la impunidad que registra el delito de reclutamiento ilícito en $\mathrm{Co}^{-}$ lombia, expresado en las pocas condenas reportadas. Es recomendable que se diseñen mecanismos, planes y programas que permitan la aplicación de las leyes existentes, que no siga el legislativo emitiendo normas y discutiendo sobre cuál es el sistema normativo más conveniente de aplicar, sino que se creen estrategias con las que se cumplan los pactos internacionales ratificados por el Estado colombiano sobre el tema. Además, que se aplique el marco normativo nacional, el cual desde la Constitución protege a los menores de manera prevalente, entendiendo que la inserción de los menores a la guerra hace parte del conflicto armado, por lo que debe ser tema de conversación de los acuerdos de paz con las guerrillas para acabar con la impunidad en este delito. Por la normatividad existente en el país, los responsables de ese ilícito no necesariamente deben ser condenados a prisión, existen otras formas de condena que pueden llevar a que se termine con esta práctica. Un elemento que podría debatirse al respecto, es incorporar a la normatividad nacional la responsabilidad penal de las personas jurídicas, lo cual haría posible condenar 
a los grupos armados de manera colectiva y contemplar penas y sanciones que los obligue de manera efectiva a no repetir tales acciones.

Se recomienda impulsar campañas masivas que eduquen a la sociedad colombiana sobre la importancia de separar a los menores de la guerra, en concordancia con la protección prevalente de los derechos de los niños establecida en la Constitución de 1991, las cuales pueden partir de la evaluación de los resultados de la divulgación de la cartilla Prevenir el reclutamiento y la utilización: una tarea de todos de la Comisión Intersectorial.

\section{Referencias}

Amaya, Á. (2013). Derecho de los derechos humanos y derecho global. Bogotá, Colombia: Editorial Ibáñez.

Arboleda, M., y Ruiz J. (2008). Manual de derecho penal, partes general y especial. Bogotá: Editorial Leyer, novena edición.

Barrero, J. (2013). Jurisprudencia constitucional, precedentes judiciales de la humanidad, casos y materiales. Bogotá, Colombia: Editorial Ibáñez.

Córdoba, M. (2013). Respuesta. Asunto: Derecho de petición-Reclutamiento ilícito. Radicado No. 20135000326041. Oficio No. 12/11/2013. Bogotá: Dirección Nacional de Fiscalías.

Herrera, K. (2013, 7 de noviembre). Respuesta al derecho de petición del 30 de octubre de 2013. Solicitud relacionada con el delito de reclutamiento ilícito. OFI13-00133639/JMSC 34020. Presidencia. Bogotá: Programa presidencial de DDHH y DIH. Dirección. .

Olano, H. (2006). Constitución Política de Colombia. Bogotá: Ediciones Doctrina y Ley, séptima edición.

Pabón, P. (2012). Manual de Derecho Penal. Tomo I. Parte general. Bogotá: Ediciones Doctrina y Ley, octava edición.

\section{Ediciones de un libro}

Ministerio de Política Territorial y Administración Pública. Agencia Estatal de Evaluación de Políticas Públicas y Calidad de los Servicios. (Ed.). (2010). Fundamentos de evaluación de políticas públicas. Madrid, España.

\section{Artículos de revista en formato electrónico}

Arango, M. (2006). Bloque de Constitucionalidad en la Jurisprudencia de la Corte Constitucional Colombiana. Disponible en http://www.icesi.edu.co/contenido/pdfs/C1C-marangobloque.pdf 
Blacio, A. (s.f.). La Acción de Tutela en Colombia. Ámbito Jurídico.com.br. Disponible en http:// www.ambito-juridico.com.br/site/?n_link=revista_artigos_leitura\&artigo_id=11418

Corporación Excelencia en la Justicia. (2013). Confianza y uso de la acción de tutela en Colombia. Disponible en http://www.cej.org.co/index.php/justiciometros 3/3582-confianza-y-uso-de-la-accion-de-tutela-en-colombia

Castillo, F. (2009). La incidencia de la acción de tutela en la implementación de las políticas públicas. Vniversitas, 119, 35-54. Bogotá, Colombia. Disponible en http://www. javeriana.edu.co/juridicas/pub_rev/documents/08-LAINCIDENCIADELAACCIONDETUTELA_000.pdf

Defensoría del Pueblo Colombia. (2013). Defensoría delegada para la prevención de riesgos de violaciones de DDHH y DIH. Disponible en http://www.defensoria.org.co/ red/?_item=040303\&_secc=04\&ts=11

Defensoría del Pueblo Colombia. (2013). Defensoría delegada para los derechos de la niñez, juventud y las mujeres. Disponible en http://www.defensoria.org.co/ $\mathrm{red} /$ ?_item=040301\&_secc=04\&ts=1

Defensoría del Pueblo Colombia. (2013). Defensoría delegada para el seguimiento a las politicas públicas en derechos humanos. Disponible en http://www.defensoria.org.co/ $\mathrm{red} /$ ?_item $=040306 \& \_\mathrm{secc}=04 \& \mathrm{tts}=1$

Eltiempo.com. (2012, 4 de agosto). Cada cinco minutos hay una tutela en el sector de la salud. Redacción salud. Disponible en (http://webcache.googleusercontent.com/ search?q=cache:dSc8Ngq_NZ4J:www.eltiempo.com/vida-de-hoy/salud/ARTICULOWEB-NEW_NOTA_INTERIOR-12096201.html+\&cd=4\&hl=es\&ct=clnk\&gl=co)

Europa Press. (Ed.). (2013). Colombia. Menores de edad figuran como los principales infractores de delitos en Colombia. Disponible en http://www.europapress.es/latam/ colombia/noticia-colombia-menores-edad-figuran-principales-infractores-delitoscolombia-20130803175122.html

ICBF. (2013a). Bienestarina. Disponible en http://www.icbf.gov.co/portal/page/portal/ PortallCBF/Bienestar/Bienestarina

ICBF. (2013b). Colombia. Grupos armados ilegales tienen niños y niñas desde la Primera Infancia y los someten desde los seis años. Bogotá. Disponible en (http://www.icbf.gov.co/portal/ page/portal/Descargas1/Prensa1/Com_Desvinculados_220413-A.pdf)

Nuevo Herald. (2004). Miles de niños colombianos están vinculados a la guerra. Disponible en http://www.latinamericanstudies.org/farc/farc-kids-1-31-04.htm

Oficina del Alto Comisionado de las Naciones Unidas para los DH OACNUDH-UNHCHR. (2003). Comunicados de prensa del 2003: se resalta importancia del defensor del pueblo. 
Disponible en http://www.hchr.org.co/publico/comunicados/2003/comunicados2003. php3? cod=17\&cat $=16$

Portafolio.co. (2011). Lucha contra la corrupción no muestra resultados esperados. Disponible en http://www.portafolio.co/economia/lucha-contra-la -corrupcion -no-muestra- resultados-esperados

Semana. (2012). Los niños y el conflicto armado en Colombia: el retrato de la infamia. Disponible en http://www.semana.com/nacion/articulo/los-ninos-conflicto-armado -colombia-retrato-infamia/257431-3

Territorio Chocoano. (2011). Bienestarina para alimentar a los niños del Chocó se vende para engordar marranos Disponible en http://www.territoriochocoano.com/secciones/ orden-publico/1799-bienestarina-para-alimentar-a-los-ninos-del-choco-se-vendepara-engordar-marranos.html

\section{Libros electrónicos}

Coalición contra la vinculación de niños, niñas y jóvenes al conflicto armado en Colombia. (2009a). El Delito Invisible. Criterios para la investigación del delito del reclutamiento ilícito de niños y niñas en Colombia. Bogotá, Colombia. Disponible en http://www.coalico.org/ archivo/LDelitoinvisible.pdf

Coalición contra la vinculación de niños, niñas y jóvenes al conflicto armado en Colombia. (2009b). Informe alterno al informe del Estado colombiano sobre el cumplimiento del Protocolo Facultativo Relativo a la Participación de Niños en los Conflictos Armados. Bogotá, Colombia. Disponible en http://www.coalico.org/archivo/IA10_EspIng.pdf

ICBF. (2012, diciembre). Observatorio de la niñez, No. 3. Vulnerabilidad, reclutamiento y utilización de los niños, niñas y adolescentes por grupos armados organizados al margen de la ley. Bogotá. Disponible en http://www.icbf.gov.co/portal/page/portal/PortallCBF/ Bienestar/Programas\%20y\%20Estrat\%C3\%A9gias/ObservatorioBienestar/Boletines/ OBSERVATORIONINEZ_N3.pdf

Springer, N. (2012). Como corderos entre lobos. Del uso y reclutamiento de niñas, niños y adolescentes en el marco del conflicto armado y la criminalidad en Colombia. Bogotá. Primera 
Edición. Disponible en http://www.centrodememoriahistorica.gov.co/descargas/informe_comoCorderosEntreLobos.pdf

Uprimny, R. (2006). El bloque de constitucionalidad en Colombia. Un análisis jurisprudencial y un ensayo de sistematización doctrinal. Disponible en http://www.wcl.american.edu/ humright/hracademy/documents/Clase1-Lectura3BloquedeConstitucionalidad.pdf

Vicepresidencia de la República. (2011). Prevenir el reclutamiento y utilización de niños, niñas y adolescentes es asunto de todos. Versión resumida documento conpes 3673 de 2010. ISBN: 978-958-8469-55-3. Bogotá. Disponible en http://www.vicepresidencia.gov. co/Iniciativas/Documents/Conpes-3673-cartilla.pdf

\section{Ediciones de un libro formato electrónico}

Giraldo, M. (Ed.). (2013). Cartilla: Entornos protectores para prevenir el reclutamiento de niñas, niños y adolescentes en Colombia. Colombia. Disponible en http://www.derechoshumanos. gov.co/Documents/130723-ENTORNOS\%20PROTECTORES\%20CD.pdf

\section{Leyes o decretos}

República de Colombia 2000. Decreto 2737 de 1989, Código del Menor. Página web de la Secretaría del Senado. Disponible en http://www.secretariasenado.gov.co/senado/ basedoc/codigo/codigo_menor.html

República de Colombia 2000. Constitución Política de Colombia. Página web de la Secretaría del Senado. Disponible en http://www.secretariasenado.gov.co/senado/basedoc/ cp/constitucion_politica_1991.html

República de Colombia 2000. Ley 599 de 2000, Código Penal. Página web de la Secretaría del Senado. Disponible en http://www.secretariasenado.gov.co/senado/basedoc/ley/2000/ ley_0599_2000.html

República de Colombia 2000. Ley 1098 de 2006, Código de la Infancia y la Adolescencia. Página web de la Secretaría del Senado. Disponible en http://www.secretariasenado.gov. co/senado/basedoc/ley/2006/ley_1098_2006.html 